\title{
Synthesis and Characterization of Wool Keratin/Hydroxyapatite/Alginate Composites
}

\author{
Jing Zhu*, Jia-Shen $\mathrm{Li}^{*}$ \\ The University of Manchester, Oxford Road, Manchester, M13 9PL, UK
}

\begin{abstract}
Interests in $\mathrm{HA} /$ polymer composites for bone tissue engineering have escalated due to their excellent biological response to damaged tissues. HA/polymer composites have been researched as potential implant in bone defects and voids. In this paper, HA was co-precipitated with two polymers including wool keratin and alginate. By changing the concentrations of wool keratin solution, alginate solution and $\mathrm{Ca}^{2+}$ and $\mathrm{PO}_{4}^{3-}$ solution, the ratios of inorganic and organic phase were changed. The final result shows that HA embedded in the organic phase well and HA nanoparticles grown on the surface of wool keratin and linear alginate macromolecules formed cross-linking around $\mathrm{Ca}^{2+}$ of $\mathrm{HA}$ nanoparticles.
\end{abstract}

Keywords: Hydroxyapatite; Wool keratin; Alginate; Nanocomposite; Biomimetic

\section{Introduction}

Bone takes an important role in the human body for protection, movement and support [1]. A natural bone is mainly composed of collagen and calcium phosphate. Collagen as microfibers provides a matrix with net-like mass structure, taking up 17\%-20\% of bones [2]. Calcium phosphate, accounting for $69 \%-80 \%$ of bones, is in the presence of crystallized hydroxyapatite (HA) and amorphous calcium phosphate $(\mathrm{ACP})^{18}[2]$. HA crystals are parallel to the collagen fibres along the long axis [2]. Bone diseases such as osteoarthritis, osteomyelitis and osteoporosis have troubled patients for a long time, leading to bone defects or voids [1]. Bone defects with non-union and critical-sized defects must be treated by filling substitutionary materials, and mechanical fixation does not work [1]. Traditional approaches to treating bone defects are autogenous bone grafting and allograft, possibly contributing to complication or infections [1]. Based on demands for improving the treatment of bone defects and voids, bone tissue engineering was proposed to enhance the biological response to damaged tissues with engineering principles $[1,3]$. Ideal implants used in the bone tissue engineering must mimic the natural environment to facilitate physiological responses [1]. For satisfying biomimetic requirements, implants used in bone tissue engineering should have following properties: proper mechanical support, bone cell migration facilitation, osteoconductivity, osteoinductivity, cellular activity enhancement, controllable

\footnotetext{
*Corresponding author.

Email addresses: jing.zhu-10@postgrad.manchester.ac.uk (Jing Zhu), jiashen.li@manchester.ac.uk (Jia-Shen Li).
} 
degradability, non-toxic degradation, controllable drug delivery and no active chronic inflammatory response [1]. Thus, many biomaterials including ceramic, metals, polymers and composites have been studied. Among of these materials, ceramics especially HA and polymers especially natural polymers have become the most potential materials. HA/natural polymer composites due to its excellent properties emerged as ideal implants for treatments of bone defects [1]. HA with $1.67 \mathrm{Ca} / \mathrm{P}$ molar ratio is the most stable phase of calcium phosphate between $\mathrm{pH} 4.0$ to $\mathrm{pH} 12.0[4,5]$. HA can be easily obtained, extracted from cortical bovine bone or prepared by wet reaction or solid state reaction [2]. Synthetic nano-sized HA, with similar structures of biological apatite, is nearly identical as mineral HA of natural bones [5]. It has good biocompatibility and osteoconductivity [6, 7]. The presence of synthesis HA in the implant is the key for improving the biological response since it can simulate the Ca-P rich layer of natural bones for mineralization of ions [8]. Natural polymers are often collagen, alginate, chitosan and gelatine [9]. These natural polymers have good degradation property, biocompatibility and non-toxicity $[1,10]$. Meanwhile, they can enhance cell attachment and provide an organic phase for simulating the 'ceramic-organic' system of natural bones [2, 9].

Most of papers researched natural HA/collagen composites for their similar compositions of natural bones. For instance, in vitro collagen mineralisation, thermally-triggered assembly of $\mathrm{HA} /$ collagen gels and vacuum infiltration of collagen into a HA matrix and etc. are common HA/collagen composites [11]. Collagen can be only extracted from natural extractions such as skin, tendon, and derivatives from human placenta and marine sources [11]. Isolation and purification of collagen require precise operation because collagen easily dissolves when covalent crosslink exists [12]. Due to its complex extraction and single source, collagen is high-priced [12]. What is more, it must be handled with in addition to removing antigenic sites, and its hydrophilicity contributes to swelling and releasing drug faster [12]. Although natural collagen can reduce risks of rejections and has very excellent biocompatibility and biodegradability, it is not quite suitable for applications in bone diseases due to high cost and antigenicity. Therefore, HA/collagen composites are hard to promote. Alginate is a linear non-repeating negatively charged copolymer belongs to polysaccharides [13]. Alginate usually exists as hydrogels, which are composed of hydrophilic polymers with 3D cross-linked networks, similar to the macromolecular-based components in the body [13]. So it is potential in drug delivery. In the presence of $\mathrm{G}$ blocks, divalent cations such as $\mathrm{Ca}^{2+}, \mathrm{Ba}^{2+}$ or $\mathrm{Sr}^{2+}$ can interact with $\mathrm{G}$ monomers by ionic bridges [13]. Then the polymer chains form cross-links like a model of egg-box [13]. Usually, $\mathrm{Ca}^{2+}$ is used as the agent to form hydrogels because of nontoxicity. Alginate has a number of hydrophilic groups like - $\mathrm{OH}$ so that its gelation is not stabilised and cannot be controlled well [13]. Alginate has good biocompatibility but lacks enough mechanical properties for load bearing at the first stage of fixation [13]. For HA/alginate composites, the common way to combine HA and alginate is cross-linking method that mixing synthetic HA powders with aqueous sodium alginate solution [13, 15]. Due to the good ability of drug delivery of alginate, HA/alginate composites aim at delivering drugs. Organic materials combine with inorganic materials by electrostatic interactions and hydrogen bonding [16]. These reactions have been proved they can improve mechanical properties, degradation and swelling behaviour [16]. As for its limitations, the fundamental problem is there is no collagen or similar materials in this system, which reduces repair efficiency of HA/alginate composites.

Alginate and collagen are most selected to combine with HA as HA/natural polymer composites. Other HA/natural composites such as HA/chitosan composites and HA/gelatine composites have similar advantages and disadvantages. Although HA/chitosan composites are potential bone implant materials with good osteoconductivity, osteoinductivity and osteogenictity, issues with 
poor mechanical properties still need to be improved [17]. Gelatine is derived from collagen and belongs to the protein group. HA/gelatine composites have similar properties as $\mathrm{HA} /$ collagen composites such as good biocompatibility and tailored degradation time. But the process for deriving gelatine needs some time and its combination with HA cannot improve the mechanical properties [18, 19]. Herein, composites of two materials are common and very few papers studied composites of more than two materials. Most of them focused on mimicking the environment of natural bones and ignored drug delivery. Besides that, many studies utilised HA powders to blend with natural polymers simply. Interactions between organic and inorganic phase are very limited, and composites prepared by this way are not identical to natural bones. Considering these advantages and disadvantages, alginate and wool keratin were selected to combine with HA by in-situ co-precipitation. Wool keratin belongs to proteins with readily availability and low price [20]. Wool keratin is extracted from wool fibres composed of 7\%-20\% half-cysteine residues of total amino acid residues [20]. Its mechanical properties are relatively higher than collagen and alginate [20]. Besides that, it is helpful for growth and proliferation of cells [20]. It is noticed that its degradation is lower than alginate and collagen, which can ensure interface force with other inorganic materials for a period [20]. Aqueous keratin solution can chelate divalent cations such as $\mathrm{Ca}^{2+}$ because of active groups like carboxyl and carbonyl groups [21].

The purpose of this report is to create a composite similar to the 'ceramic-organic' system of natural bones to accelerate bone regeneration. Therefore, in this report, HA will be in-situ co-precipitated with alginate and keratin for better interaction between organic and inorganic phases. The presence of alginate provides the possibility of delivering drugs. Composites with different ratios of HA and natural polymers will be compared and analysed. In this paper, some biological tests and degradation tests did not be conducted. These two kinds of tests will be performed in the further study.

\section{Materials and Experimental Method}

\subsection{Materials}

Wool powders were purchased commercially. Alginate powders, sodium hydroxide (NaOH), hydrochloric acid $(\mathrm{HCl})$, calcium chloride $\left(\mathrm{CaCl}_{2}\right)$, and sodium dihydrogen phosphate $\left(\mathrm{NaH}_{2} \mathrm{PO}_{4}\right)$ were all analytical grade and bought from Sigma-Aldrich. Water used in this experiment was deionised water.

\subsection{Fabrication of Wool Keratin/Ha/Alginate Nanocomposites and Characterization}

$1 \mathrm{~g} / \mathrm{L}$ wool keratin solution was made by adding $1 \mathrm{~g}$ wool powders into $1 \mathrm{~L} \mathrm{NaOH}$ solution $(\mathrm{pH}$ $=14.0$ ) and then $\mathrm{HCl}$ was added to neutralise the wool keratin solution to $\mathrm{pH}=7.0$. Other concentrations of wool keratin solution including $0.5 \mathrm{~g} / \mathrm{L}$ and $0.25 \mathrm{~g} / \mathrm{L}$ can be diluted from 1 $\mathrm{g} / \mathrm{L}$ wool keratin solution. For preparing $2 \% \mathrm{w} / \mathrm{v}, 1 \% \mathrm{w} / \mathrm{v}, 0.5 \% \mathrm{w} / \mathrm{v}$ alginate solution, $2 \mathrm{~g}, 1 \mathrm{~g}$, $0.5 \mathrm{~g}$ alginate powders were dissolved in $100 \mathrm{ml}$ deionised water respectively and stirred at the speed of 3. Wool keratin/HA/alginate composites were synthesised by in-situ co-precipitation. For preparing a composite of $1 \mathrm{~g} / \mathrm{L}$ wool keratin, $2 \%$ alginate and $\mathrm{HA}, 100 \mathrm{ml} \mathrm{CaCl}$, solution $(0.1$ 
$\mathrm{mol} / \mathrm{L}, 0.05 \mathrm{~mol} / \mathrm{L}$ and $0.025 \mathrm{~mol} / \mathrm{L}$ ) was mixed with $200 \mathrm{ml}$ wool keratin solution for 20 minutes. Meanwhile, $20 \mathrm{ml} 2 \%$ alginate solution was mixed with $60 \mathrm{ml} \mathrm{NaH} \mathrm{PO}_{4}(0.1 \mathrm{~mol} / \mathrm{L}, 0.05 \mathrm{~mol} / \mathrm{L}$ and $0.025 \mathrm{~mol} / \mathrm{L})$. The ratio of $\mathrm{Ca}^{2+}$ and $\mathrm{PO}_{4}^{3-}$ was set as 1.67 at this stage. After 20 minutes, keratin $/ \mathrm{CaCl}_{2}$ solution was poured into alginate $/ \mathrm{NaH}_{2} \mathrm{PO}_{4}$ solution slowly under constant gentle speed and mixed for $1 \mathrm{~h}$. NaOH solution was added slowly to adjust pH to 10.0. After $24 \mathrm{~h}$, keratin/HA/alginate co-precipitation was on the bottom of the beaker. The precipitation was centrifuged at $9500 \mathrm{rpm}$ for $4 \mathrm{~min}$ and then washed for five times. Other concentrations of keratin/HA/alginate composites were prepared as same as above procedure. Pure HA particles were also synthesised for later characterizations.

Precipitations of keratin/HA/alginate composites were dropped onto aluminium films and pasted onto a carbon tab. Samples were coated by $3 \mathrm{~nm}$ of $\mathrm{Au} / \mathrm{Pd}$ for observing secondary electron images (SEM, FE6-JEM, XL30, Philips) at $8 \mathrm{kV}$. Prepared HA powders, pure alginate powders, pure keratin powders and keratin/HA/alginate composites were mixed with potassium bromide (KBr) with 1:20 mass ratio and grounded in an agate mortar respectively. FTIR data were recorded by a Fourier transform infrared spectrometer (Nicolet 5700). Crystallinity and structure of keratin/HA/alginate composites, pure prepared HA powders, pure alginate powders and pure keratin powders were analysed by X-ray diffractometer (XRD5, PANaytical X'Pert Pro) in the $2 \theta$ range of $10^{\circ} \mathrm{C}$ to $90{ }^{\circ} \mathrm{C}$. The step size was $0.033^{\circ}$ and the count rate was $100 \mathrm{~s}$ per step. Each sample (10-15 mg) including prepared HA powders, pure keratin powders and pure alginate powders were detected by thermogravimetric analysis (TGA Q500). Nitrogen flow was as the internal gas. The initial temperature was set as $25{ }^{\circ} \mathrm{C}$ for 2 min and then grown to $1000{ }^{\circ} \mathrm{C}$ with $20{ }^{\circ} \mathrm{C}$ per minute. The speed of collecting data was every $0.8 \mathrm{~s}$.

\section{Results and Discussion}

\subsection{Scanning Electron Microscopy Analysis}

Surface morphologies with magnification 10000x of composites and the morphology with magnification 100000x of pure prepared HA are shown in Fig. 1. HA nanoparticles are shown in Fig. 1(d) and Fig. 1(e) shows the ratio of $\mathrm{Ca}: \mathrm{P}$ is 1.67, which prove that HA nanoparticles were synthesized successfully. HA aggregates in the composites are observed to embed and disperse in the polymer matrix. It is hard to distinguish the interfacial boundary between HA and polymer phases, which implies miscibility between these three materials [22, 23]. HA particles cannot be individually observed because of the polymer surface cover, especially with the increase of alginate in Fig. 1. Keratin provides nucleation sites for HA and cannot control growth direction of HA, so HA crystals are formed on the surface of keratin fractions [21, 24]. From these microstructures, HA particles in the composites with $2 \%$ alginate are more obviously embedded in the organic matrix, indicating alginate is possibly around HA particles. In this case, alginate acts as a binder for HA particles. When the concentration of alginate is $2 \%$, the fusion of HA crystallites is better. HA-based implants have been reported that it is easy for HA particles to move from implanted sites in the human body. The migration contributes to risks of tissue damage, influencing effects of treatment. Considering this point, a better fusion of HA crystallites in the polymer phase advantages immobilisation of particles. The composite with $2 \%$ alginate content shows a higher level of interpenetration between these three materials, having set up a hierarchical 3D network. The only problem is composites with $2 \%$ alginate may not have a stable structure of hydrogels. 

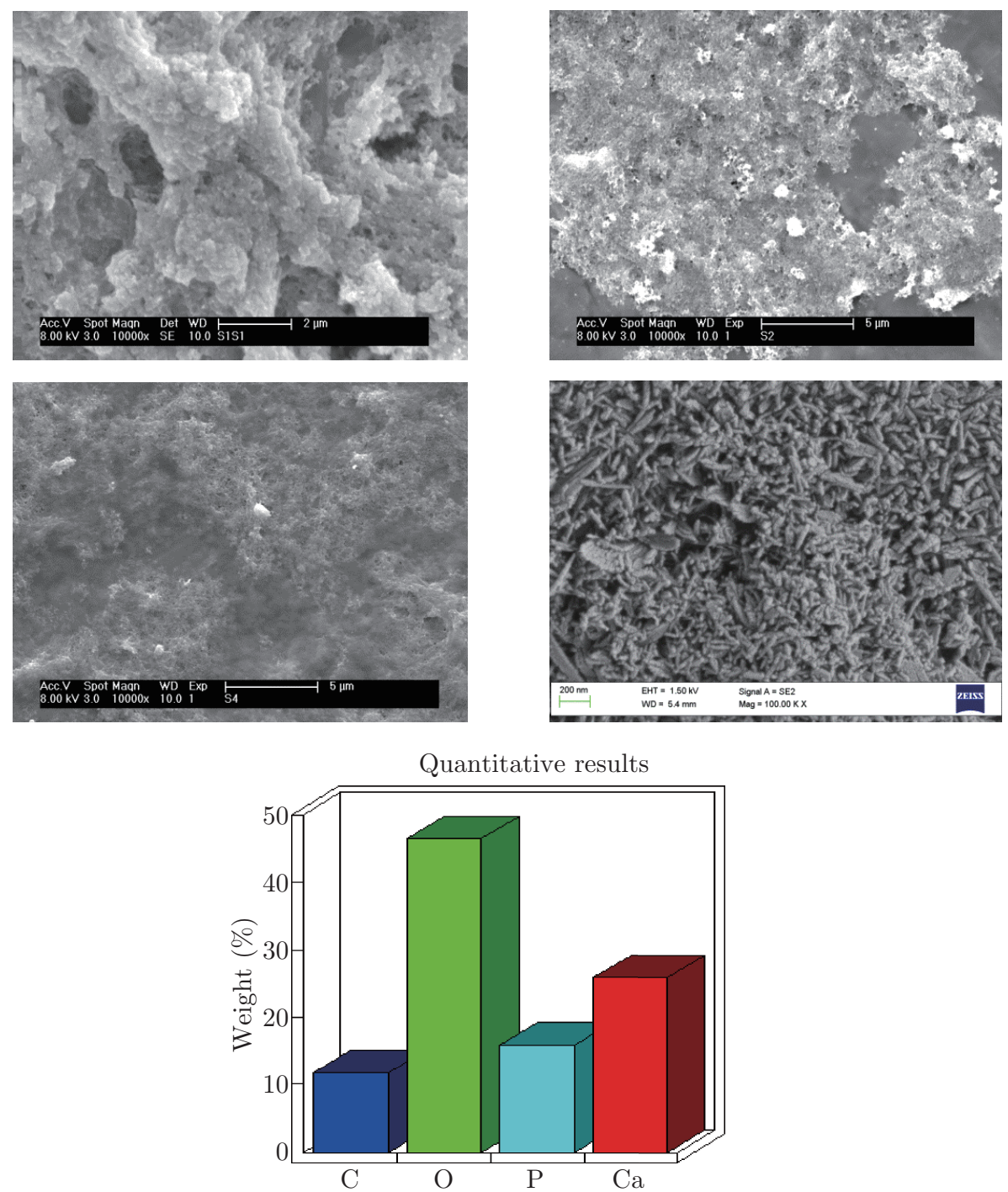

Fig. 1: SEM images of composites and prepared HA particles ((a) 1K2A0.1CA_PO4; (b) 1K1A0.1CA_PO4; (c) 1K0.5A0.1CA_PO4; (d) prepared HA particles) and EDX analysis of Ca:P ratio

\subsection{Fourier Transform Infrared Spectra Analysis}

FTIR spectra analysed chemical bonds of K/HA/A composites. In Fig. 2, it illustrates FTIR spectra of pure materials and composites. For alginate, the characteristic transmittance bands appear at 1615 and $1418 \mathrm{~cm}^{-1}$, which are related to asymmetrical and symmetrical stretching vibrations of the $-\mathrm{COO}^{-}$group $[23,25]$. For HA, there are two main types of characteristic peaks attributed to the presence of $\mathrm{PO}_{4}^{3-}$ and $\mathrm{CO}_{3}^{2-}$ groups $[21,23]$. The bands at 1114, 1034, $961 \mathrm{~cm}^{-1}$ are considered as $\mathrm{P}-\mathrm{O}$ stretching vibration, and the bands at 601 and $563 \mathrm{~cm}^{-1}$ correspond to $\mathrm{O}-\mathrm{P}-\mathrm{O}$ bending mode [21]. Carbonate ions are indicated by bands of 1401 and $875 \mathrm{~cm}^{-1}$, which are attributed to $\mathrm{C}-\mathrm{O}$ stretching mode [21]. It is because HA are partially replaced, which may result from carbon dioxide gas in the air [21]. The band at $1635 \mathrm{~cm}^{-1}$ in prepared HA is assigned to $\mathrm{H}_{2} \mathrm{O}$ group [26]. In pure wool keratin, characteristic transmittance bands are amide I, II and III peaks at $1658,1550,1251 \mathrm{~cm}^{-1}$, respectively [21]. Amide I transmittance band is attributed to $\mathrm{C}=\mathrm{O}$ stretching mode, whereas amide II band is related to bending vibration of $\mathrm{N}-\mathrm{H}$ coupled 


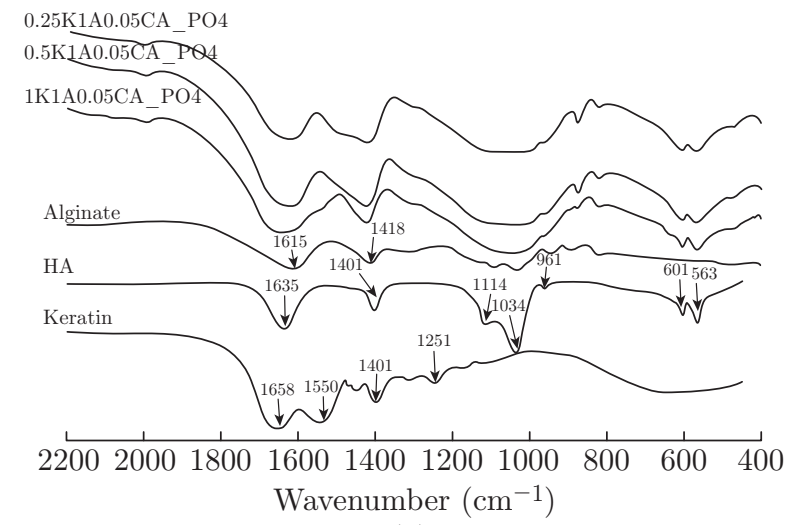

(a)

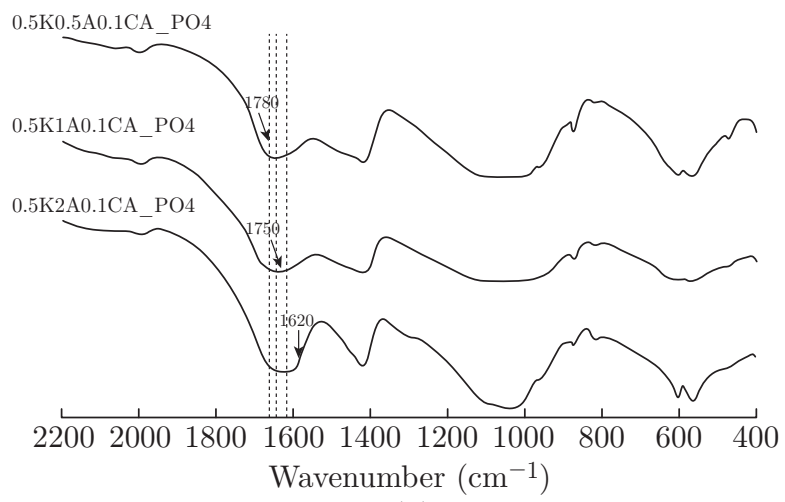

(b)

Fig. 2: FTIR spectra of (a) pure alginate, prepared HA and keratin and K/HA/A composites; (b) $\mathrm{K} / \mathrm{HA} / \mathrm{A}$ composites with different contents of alginate

with stretching vibration of $\mathrm{C}-\mathrm{N}$ and amide III band results from $\mathrm{C}-\mathrm{N}$ stretching and $\mathrm{C}=\mathrm{O}$ bending modes [13]. The band at $1401 \mathrm{~cm}^{-1}$ corresponds to bending mode of $\mathrm{C}-\mathrm{H}$ and $\mathrm{O}-\mathrm{H}$ [21].

Composites have characteristic bands similar to primary materials. In Fig. 2(a), bands of composites are wider when compared with the band from 1600 to $1700 \mathrm{~cm}^{-1}$ of primary materials. It could result from the overlap of amide $\mathrm{I}, \mathrm{H}_{2} \mathrm{O}$ and $-\mathrm{COO}^{-}$groups [26]. With ratios of keratin increasing, the peaks of the composites between 1600 to $1700 \mathrm{~cm}^{-1}$ shift nearly to the peak of amide I and the band tends to be stronger and wider while no peak of amide II is observed. These changes would be attributed to ionic interactions between negatively charged $-\mathrm{COO}^{-}$ groups of alginate and positively charged amino groups of keratin as well as chemical bonding between organic and inorganic phases such as interactions between $\mathrm{Ca}^{2+}$ and carboxyl groups [27]. The existence of intermolecular interactions between mineral substances and organic matrix controls nucleation and growth of HA. Notable bands of composites are broadening in the peak of symmetrical $-\mathrm{COO}^{-}$groups due to influences of keratin and HA. Compared with pure prepared $\mathrm{HA}$, characteristic bands of HA are also observed in these composites. However, bands from $\mathrm{PO}_{4}^{3-}$ group are wider and weaker in composites. It indicates the composition of alginate and keratin has a remarkable impact on the growth of HA. In this case, crystallinity of HA in composites could decrease, which will be confirmed in XRD analysis. Composites in Fig. 2(b) are composed of the same concentrations of wool keratin and HA but different concentrations of alginate. Bands between 1600 and $1700 \mathrm{~cm}^{-1}$ shift nearly to the peak of the carboxyl group of alginate at 1615 $\mathrm{cm}^{-1}$ with an increase of amount of alginate.

\subsection{X-ray Diffraction Analysis}

XRD patterns are shown below for comparing changes of crystallographic structure of HA in the composites. In Fig. 3, it shows XRD patterns of primary materials and composites, illustrating how organic phases impact on the crystallinity of mineral substances. The diffraction peaks of pure prepared HA are observed at $25.8^{\circ}, 31.8^{\circ}, 32.9^{\circ}, 34.1^{\circ}, 40^{\circ}, 46.8^{\circ}, 49.6^{\circ}$ and $53.5^{\circ}$ [28]. They correspond to diffraction planes (002), (211), (300), (202), (310), (222), (213) and (004) [28]. Among of these planes, planes (211), (300) and (202) are main peaks of pure HA [23].

In the diagrams of Fig. 3(a) and Fig. 3(b), the intensity of HA crystals in composites have a 

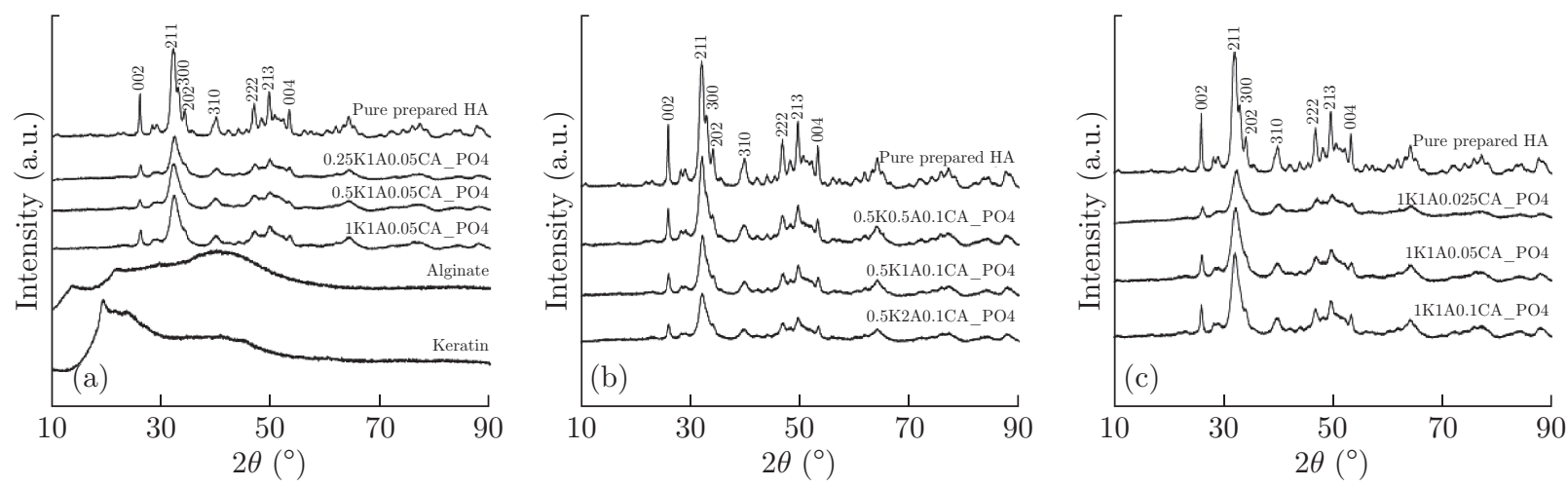

Fig. 3: XRD patterns of (a) primary materials and K/HA/A composites with different wool keratin contents; (b) pure prepared HA and K/HA/A composites with different alginate contents; (c) pure prepared HA and $\mathrm{K} / \mathrm{HA} / \mathrm{A}$ composites with different HA contents

distinct decrease but peaks of HA crystals still exist, indicating that HA is embedded well in the polymer matrix. This result supports what have been analysed in SEM and FTIR tests. The broadening peaks of composites show small size and low crystallinity of HA particles similar to mineral substances of natural bones [29]. Three reasons could cause it. One corresponds to small nuclei (nano-sized) by in-situ nucleation [30]. Moreover, molecular interactions between these three materials limit further growth of HA crystals. Furthermore, preparation methodology can also impact the crystallinity of HA particles in composites [31]. The merging of (202) and (300) peaks in composites also imply interactions between polymers and the HA lattice [14]. The intensity of peaks of composites gradually decreases as the increase of alginate contents. It is caused by the structure of composites. As mentioned, HA particles tend to be on the surface of keratin, but alginate tends to wrap HA particles.

Fig. 3(c) shows not only organic phase can influence crystallinity, but also the content of calcium ions and phosphate ions would have an impact on the crystallographic structure of $\mathrm{K} / \mathrm{HA} / \mathrm{A}$ composites.

\subsection{Thermogravimetric Analysis}

Thermogravimetric (TG) analysis was employed to detect thermal stability of the K/HA/A composite and determine influences of keratin, $\mathrm{HA}$ and alginate on the composites by comparing thermograms of three primary materials. During the heating process, the mass of prepared HA powders have slight weight loss in Fig. 4(a), while the weight of keratin and alginate sharply decreases from $220{ }^{\circ} \mathrm{C}$ to $800{ }^{\circ} \mathrm{C}$. The weight loss of HA could be attributed to dihydroxylation [28]. For alginate, the reduction of weight below $220^{\circ} \mathrm{C}$ results from water evaporation and lactonization [28]. As temperature increases, decomposition starts at around $220^{\circ} \mathrm{C}$. From $220^{\circ} \mathrm{C}$ to $280^{\circ} \mathrm{C}$, it is decomposition of $-\mathrm{COO}^{-}$of alginate [30]. In the next step, weight loss of alginate is ascribed to decomposition of hydroxyl groups [32]. After $850{ }^{\circ} \mathrm{C}$, decomposition of alginate is almost completed. The process of weight loss of wool keratin is similar to alginate. Firstly, water evaporation occurs and then wool protein molecules decompose. It was also proved that the disulphide bonds of wool would cleave from $230{ }^{\circ} \mathrm{C}$ to $250{ }^{\circ} \mathrm{C}$ and release volatile compounds including hydrogen sulphide and sulphur dioxide [33]. Moreover, $60 \%$ of the weight loses at $150{ }^{\circ} \mathrm{C}$ to $500{ }^{\circ} \mathrm{C}$ resulted from the destruction of the lateral chain of wool protein molecules [34]. 

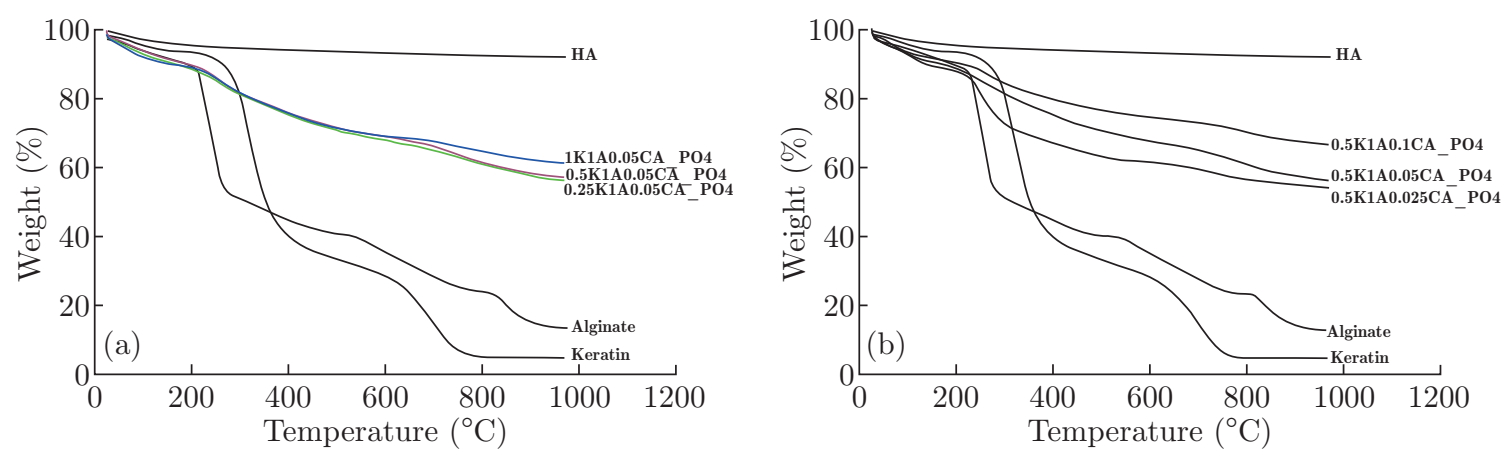

Fig. 4: TGA curves of (a) primary materials and composites with different keratin contents (Blue curve is the sample of 1K1A0.05CA_PO4; Red curve is the sample of 0.5K1A0.05CA_PO4; Green curve is the sample of 0.25K1A0.05CA_PO4); (b) primary materials and composites with different HA contents

It is evident the involvement of keratin and alginate impacts on the thermal stability due to molecular interactions such as electrostatic interactions [29]. Fig. 4(a) shows thermal stability of composites with different keratin contents. The weight of the composite loses gradually from room temperature to $250{ }^{\circ} \mathrm{C}$, and the weight has more rapid decrease above $250{ }^{\circ} \mathrm{C}$. Due to the existence of keratin and alginate in the composite, the reason of weight loss below $100{ }^{\circ} \mathrm{C}$ is ascribed to water evaporation as well. Decomposition of alginate and wool keratin almost starts at $250{ }^{\circ} \mathrm{C}$. After $850{ }^{\circ} \mathrm{C}$, the weight of the composite tends to be stable due to the presence of HA. In Fig. 4(a), there are no big differences between TGA curves. This situation supporting the results from XRD tests implies the increase of keratin doses not significantly affect crystallinity of composites since thermal stability of the composite does not change obviously. In Fig. 4(b), it is explicit that the thermal stability decreases as the reduction of HA contents.

Fig. 5 corresponds to analysis in XRD that alginate influences the crystallographic structure more. In Fig. 5(b), with the increase of alginate in the composites, their curves have more obvious differences with each other. Therefore, alginate has a greater impact on the structure and thermal stability of composites than keratin. In Fig. 5(c), it looks different compared with Fig. 5(a) and Fig. 5(b). The composite with $2 \%$ alginate should have the lowest thermal stability of these three composites, but now it has the highest thermal stability. It could be caused by high concentration of alginate. Due to the high concentration of alginate, hydrogels would form quickly with the existence of $\mathrm{Ca}^{2+}$. It means much of alginate become hydrogels by cross-linking and the thermal stability of the composite (1K2A0.05CA_PO4) would be increased.
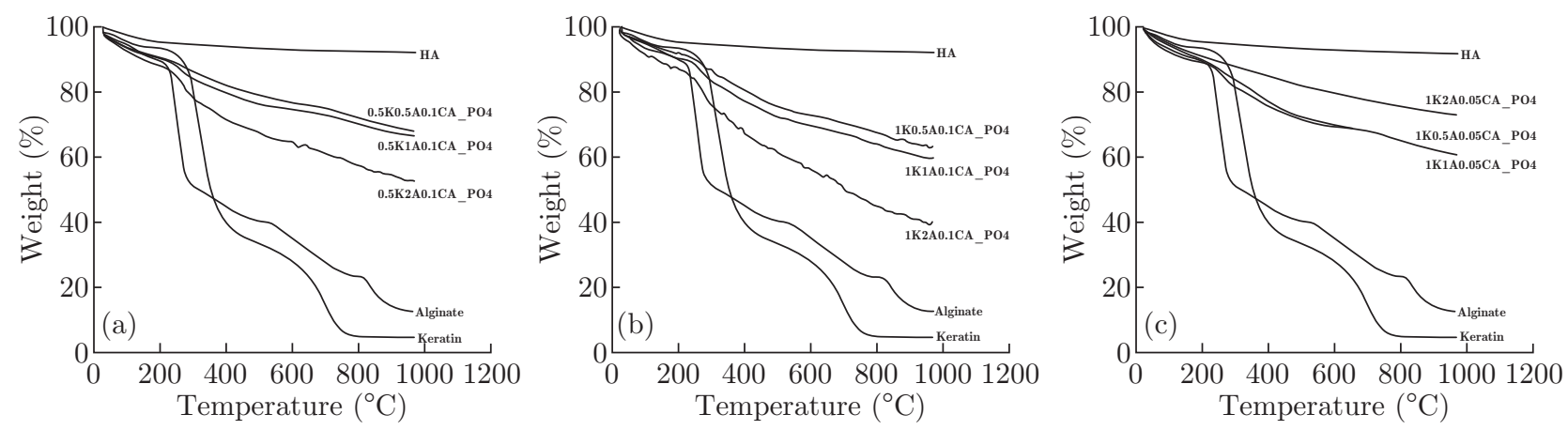

Fig. 5: TGA curves of primary materials and composites with different alginate contents 


\section{Conclusion}

The composites with nano-sized HA and bioactive alginate and keratin were successfully synthesised by in-situ co-precipitation. SEM images show that HA particles are embedding in the polymer matrix, setting up a hierarchical 3D network. When the concentration of alginate is $2 \%$, the level of interpenetration between these three materials is higher. However, composites with $2 \%$ could not have a stable structure of hydrogels. FTIR analysis shows that characteristic bands of composites are similar to those of primary materials. Especially the band between 1600 and $1700 \mathrm{~cm}^{-1}$, it will shift nearly to the peak of amide I of wool keratin or the peak of -COO- of alginate with the increase of keratin or alginate respectively. This shift confirms chemical interactions between inorganic and organic phase as well as within the internal organic phase. The influence of keratin and alginate on composites is also confirmed in the bands of phosphate groups in FTTR spectra. Some of bands for P-O bonds of HA disappear due to keratin and alginate. X-ray diffraction analysis confirms the involvement of polymer affects crystallographic structure of HA particles in the composites, which accords with microstructures in the SEM test. The influence of keratin and alginate has a little different. Thermogravimetric (TG) analysis compares thermal stability of composites and alginate impacts on the thermal stability of composites more than keratin. Due to the existence of HA, thermal stability of composites is acceptable. The stages of weight loss for composites also imply complex molecular interactions between these three materials like electrostatic interactions and hydrogen bonding. The structure of this composite can be supposed that HA particles tend to be on the surface of keratin, but alginate tends to wrap HA particles. So alginate has greater impact on the thermal stability of composites. Wool keratin plays an important role in this composite, as the alternative of collagen, mimicking the natural environment of natural bones better and also reducing the possibility of refracture because of longer degradation time. These results indicate that $\mathrm{K} / \mathrm{HA} / \mathrm{A}$ composites are potential materials for bone tissue engineering.

\section{References}

[1] Porter J R, Ruckh T T, Popat K C. Bone tissue engineering: a review in bone biomimetics and drug delivery strategies. Biotechnology Progress, 2009, 25(6): 1539-1560.

[2] Suchanek W, Yoshimura M. Processing and properties of hydroxyapatite-based biomaterials for use as hard tissue replacement implants [J]. Journal of Materials Research, 1998, 13(01): 94-117.

[3] Burg K J L, Porter S, Kellam J F. Biomaterial developments for bone tissue engineering. Biomaterials, 2000, 21(23): 2347-2359.

[4] Dorozhkin S V. Nanodimensional and nanocrystalline apatites and other calcium orthophosphates in biomedical engineering, biology and medicine. Materials, 2009, 2(4): 1975-2045.

[5] Lin K, Chang J. Structure and properties of hydroxyapatite for biomedical applications. Hydroxyapatite (Hap) for Biomedical Applications, 2015, 1: 3-19.

[6] Wahl D A, Czernuszka J T. Collagen-hydroxyapatite composites for hard tissue repair. Eur Cell Mater, 2006, 11: 43-56.

[7] Kumta P N, Sfeir C, Lee D H, et al. Nanostructured calcium phosphates for biomedical applications: novel synthesis and characterization. Acta Biomaterialia, 2005, 1(1): 65-83.

[8] Chuenjitkuntaworn B, Supaphol P, Pavasant P, et al. Electrospun poly (L-lactic acid)/ hydroxyapatite composite fibrous scaffolds for bone tissue engineering. Polymer International, 2010, 59(2): $227-235$. 
[9] Chung J H, Kim Y K, Kim K H, et al. Synthesis, characterization, biocompatibility of hydroxyapatite - natural polymers nanocomposites for dentistry applications. Artificial cells, nanomedicine, and biotechnology, 2016, 44(1): 277-284.

[10] Park J, Lakes R S. Biomaterials: an introduction. Springer Science \& Business Media, 2007.

[11] Wahl D A, Czernuszka J T. Collagen-hydroxyapatite composites for hard tissue repair. Eur Cell Mater, 2006, 11: 43-56.

[12] Friess W. Collagen-biomaterial for drug delivery. European Journal of Pharmaceutics and Biopharmaceutics, 1998, 45(2): 113-136.

[13] Lee K Y, Mooney D J. Alginate: properties and biomedical applications. Progress in polymer science, 2012, 37(1): 106-126.

[14] Sivakumar M, Rao K P. Preparation, characterization, and in vitro release of gentamicin from coralline hydroxyapatite-alginate composite microspheres. Journal of Biomedical Materials Research Part A, 2003, 65(2): 222-228.

[15] Lin H R, Yeh Y J. Porous alginate/hydroxyapatite composite scaffolds for bone tissue engineering: preparation, characterization, and in vitro studies. Journal of Biomedical Materials Research Part B: Applied Biomaterials, 2004, 71(1): 52-65.

[16] Zhang J, Wang Q, Wang A. In situ generation of sodium alginate/hydroxyapatite nanocomposite beads as drug-controlled release matrices. Acta Biomaterialia, 2010, 6(2): 445-454.

[17] Venkatesan J, Kim S K. Chitosan composites for bone tissue engineering - an overview. Marine drugs, 2010, 8(8): 2252-2266.

[18] Habraken W, Wolke J G C, Jansen J A. Ceramic composites as matrices and scaffolds for drug delivery in tissue engineering. Advanced drug delivery reviews, 2007, 59(4-5): 234-248.

[19] Bigi A, Cojazzi G, Panzavolta S, et al. Stabilization of gelatin films by crosslinking with genipin. Biomaterials, 2002, 23(24): 4827-4832.

[20] Dias G J, Mahoney P, Swain M, et al. Keratin-hydroxyapatite composites: Biocompatibility, osseointegration, and physical properties in an ovine model. Journal of Biomedical Materials Research Part A, 2010, 95(4): 1084-1095.

[21] Li J, Liu X, Zhang J, et al. Synthesis and characterization of wool keratin/hydroxyapatite nanocomposite [J]. Journal of Biomedical Materials Research Part B: Applied Biomaterials, 2012, 100(4): 896-902.

[22] Rajkumar M, Meenakshisundaram N, Rajendran V. Development of nanocomposites based on hydroxyapatite/sodium alginate: Synthesis and characterisation. Materials Characterization, 2011, 62(5): 469-479.

[23] Wang L, Li Y, Li C. In situ processing and properties of nanostructured hydroxyapatite/alginate composite. Journal of Nanoparticle Research, 2009, 11(3): 691-699.

[24] Li J S, Li Y, Liu X, et al. Strategy to introduce a hydroxyapatite-keratin nanocomposite into a fibrous membrane for bone tissue engineering. Journal of Materials Chemistry B, 2013, 1(4): 432-437.

[25] Zhang J, Wang Q, Wang A. In situ generation of sodium alginate/hydroxyapatite nanocomposite beads as drug-controlled release matrices. Acta Biomaterialia, 2010, 6(2): 445-454.

[26] Li J, Li Y, Li L, et al. Fabrication and degradation of poly (l-lactic acid) scaffolds with wool keratin. Composites Part B: Engineering, 2009, 40(7): 664-667.

[27] Jin $\mathrm{H} \mathrm{H}$, Lee $\mathrm{C} \mathrm{H}$, Lee W K, et al. In-situ formation of the hydroxyapatite/chitosan-alginate composite scaffolds. Materials Letters, 2008, 62(10): 1630-1633.

[28] Chang C, Peng N, He M, et al. Fabrication and properties of chitin/hydroxyapatite hybrid hydrogels as scaffold nano-materials. Carbohydrate polymers, 2013, 91(1): 7-13. 
[29] Han J, Zhou Z, Yin R, et al. Alginate-chitosan/hydroxyapatite polyelectrolyte complex porous scaffolds: Preparation and characterization. International journal of biological macromolecules, 2010, 46(2): 199-205.

[30] Tampieri A, Sandri M, Landi E, et al. HA/alginate hybrid composites prepared through bioinspired nucleation [J]. Acta biomaterialia, 2005, 1(3): 343-351.

[31] Murugan R, Ramakrishna S. Bioresorbable composite bone paste using polysaccharide based nano hydroxyapatite. Biomaterials, 2004, 25(17): 3829-3835.

[32] Liang Y H, Liu C H, Liao S H, et al. Cosynthesis of cargo-loaded hydroxyapatite/alginate coreshell nanoparticles (HAP@Alg) as pH-responsive nanovehicles by a pre-gel method. ACS applied materials \& interfaces, 2012, 4(12): 6720-6727.

[33] Idris A, Vijayaraghavan R, Rana U A, et al. Dissolution and regeneration of wool keratin in ionic liquids. Green Chemistry, 2014, 16(5): 2857-2864.

[34] Li R, Wang D. Preparation of regenerated wool keratin films from wool keratin-ionic liquid solutions. Journal of Applied Polymer Science, 2013, 127(4): 2648-2653. 